\title{
Building Sustainability Resiliency During Post Covid World Focusing ESG And Climate Risk Issue
}

\author{
Maria Afreen 1 (D) \\ ${ }^{1}$ Faculty of Economics and Business, University Malaysia Sarawak, Sarawak, Malaysia
}

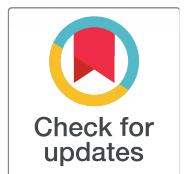

Keywords: Sustainability, ESG, Climate Risk, COVID-19, Financial Distress.

\section{Received Date: \\ 08-05-2021 \\ Accepted Date: \\ 04-09-2021 \\ Publication Date: \\ 30-09-2021}

\section{ABSTRACT}

Purpose of this study: In accordance with the current world economy, building climate sustainability resiliency is very important under the physical risk and transitional risk mitigation. This classification of climate risks could have an enormous positive impact focusing on ESG (Environmental, Social and Corporate Governance) goal achievement during the post-COVID pandemic situation focusing on climate risk issues. The European Green Deal has also increased the EU's climate ambitions. In addition, global cooperation on sustainable finance has increased and the international context has changed. The financial sector will play a critical role in our transition to sustainability.The strategy of this study aims to support the European Green Deal aims, as well as an inclusive and sustainable recovery from the COVID-19 pandemic consequences.

Methodology: In this study, the relative carbon risk and absolute carbon risk is shown based on the dynamic common factor model. The graphical representation of absolute versus relative carbon risk is measured in this time series data based research on the ten years timeline of 2010 to 2019.

Main findings: The study shows the graphical figure regardingregion-wise dynamics of the relative and absolute carbon emissions risk in an average by adopting the dynamic common factor model throughout the global level by obtaining the Kalman filtering tool.

Research limitations/Implications: Lack of resources of primary data is the main creating hindering effect that is faced in this study. This article portrays the increase in $\mathrm{CO} 2$ emissions leading to consequences of climate risk also accelerating these problems within the regions and countriesmentioned in this research.

Novelty/Originality: Due to the COVID-19 outbreak, the developed nations, as well as emerging economies, are facing vulnerability in the area of financial, governmental, environmental to be sustainably resilient. This is the high time of detecting these problems and taking precautionary measures by the policymakers and government in the economic sector by adopting implementable methodologies. This study may benefit readers by advancing the existing knowledge or creating new knowledge in this subject. The current study reflects the situation of forthcoming researchers who intends to study as well as interested in this particular area.
Copyright: (c) 2021. The Authors. Licensee: IJSSER. This work is licensed under the Creative Commons Attribution License.

Please cite this article as: Maria, A. (2021). Building Sustainability Resiliency During Post Covid World Focusing ESG And Climate Risk Issue. International Journal of Social Sciences and Economic Review, 3(3), 21-27.

doi.org/10.36923/ijsser.v3i 3.108 .

\section{Read online:}

Scan this QR code with your smart phone or mobile device to read online.

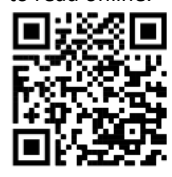

\section{INTRODUCTION}

Over the previous decades, we've eventually seen significant financial growth, growing GDP and remarkable innovation within business and technology. nevertheless, this progress chronologically has led towards negative shock externalities over the planet and people, contributing towards rapid climate change as well as growing inequality. The adverse effects have been additionally exacerbated through the COVID-19 outbreak, which reversely affected the millions of numbers of people, in accordance to the poor as well as vulnerable being clouted the hardest (Afreen, 2021).

The subsequent stated remarkable notes are made up to be signified in this research focusing towards possible precautionary remedies (Ahmad, 2021). How can we "rewire" our sector of economies so that they are functional for all? The particular key actions to be undertaken by governments as well as the sector in private industry are researched here. Also how it could be addressed climate change as well as inequality, while structuring back comparatively better afterwards the pandemic is inaugurated here. Climate change riskis classified into either physical or transition risks. Physical risks arise from the changes in weather and climate that impact economies. Transition risk drivers arise as a result of transitioning an economy that is reliant on fossil fuels to a low-carbon economy.

To deal with the wicked problems regarding climate change as well as inequality, additionally, to assure that we construct back better afterwards the COVID-19 outbreak, we require a particular, as well asthe systemic remarkable change to the way, paves the economies work. 


\section{LITERATURE REVIEW}

Hong et.al (2019) showed Climate risks and market efficiency demonstration in their study. Ilhan et. al (2019) illustrated the institutional investors' views and preferences on climate risk disclosure in their study. Kolbel et. al (2021) discussed physical and transition climate risk in their research. Krueger (2020) showed the importance of climate risk for institutional investors. Liu et. al (2019) constructed climate risk-related research. Luccioni and Palacios (2019) demonstrated natural language processing to portray climate risk exposure. Marquis et. al (2016) conducted a global study on green-washing. McFarland (2009) researched climate change risk disclosure. Michaels and Gruning (2017) constructed the relationship of corporate social responsibility disclosure on information asymmetry and the cost of capital that is related to climate risk exposure. NGFS (2019a) studied climate change as a source of financial risk, NGFS (2019b) demonstrated the macroeconomic and financial stability implications with climate change. Nowiski (2018) researched climate risk disclosure and its current and future relevance to the energy sector. Sautner et.al (2020) researched m-level climate change exposure. In 2017 and 2020 , the TCFD (Task Force on Climate-related Financial Disclosures) released its ultimate report with remedial recommendations for the climate-related disclosures which could promote much-informed investment, the credit, and insurance-related decisions as well as, in return, enable the stakeholders to improved understand the financial hierarchy system's exposure towards climaterelated risks. Varini et. al (2020) demonstrated in their study regarding tackling climate change assessment with a machine learning approach.

The Bank for International Settlements (BIS) has inaugurated the euro-denominated, open-ended fund for the green bond concerning investments by the central banks as well as official regulatory institutions. The launch follows towards the successful prologue of a foremost BIS green bond fund compellation in US dollars in September 2019. Together, the two BIS green bonds concerning funds will administer some $\$ 2$ billion in the green bonds in favor of central banks with the prospect that the concerning funds will prolong to rise noticeably. The funds already have been significantly developed with the support of the advisory committee strained from a worldwide group of the central banks. They are within the part of the BIS's green bond fund specific initiative, which stimulates central banks towards the incorporation of environmental sustainability-focused objectives within the management in regard of their reserves as well as the capital, in the line with the particular growing necessity of demand in regard of climate-friendly proactive investments amongst official institutions (Varini et. Al., 2020).

The funds support green finance by making significant investments in environmentally friendly projects such as renewable energy production and energy efficiency, as well as providing support for the adoption of best market practices and reporting standards for the development of the specific green bond market. The two concerning funds are specifically structured in accordance to Swiss law as well as belong to significantly the BIS Investment Pool (BISIP) family, a format generally used by the BIS Asset Management concerning its fixed earning investment concerning products. They are coordinated in-house through BIS Asset Management. Eligible bonds possess a minimum specific rating stated as A- and meet the terms with the International Capital Market Association's Green Bond Principles and the Climate Bond Standard available by the Climate Bonds Initiative. In addition, the BIS publishes an annual impact report for investors based on information provided by issuers in relation to bonds in which the funds invest (사reen, 2020).

In keeping with its participation in the global Central Banks and Supervisors Network on Greening the Financial System, the BIS is committed to supporting specific environmentally responsible finance and investing practices. Peter Zöllner, Head in charge of the BIS Department of Banking, said: "Central banks around the globe have continued to support this joint green bond fund initiative and channel funds into the green bond market through the BIS. In line with the initiative's objectives, we are continuing our dialogue with green bond issuers and remain committed to supporting the adoption of best market practices, including improved impact reporting, to deepen the green bond market."

\section{METHODOLOGY}

Scenario methodologies analysis have eventually become broadly available, varying within the scale, time horizon, scope and complexity. Few methodologies inevitably consider both physical and transition risks in an integrated manner. And still, if they specifically do, difficulty makes it much complex to implement. Institutions appear in a trade-off between practicality and comprehensiveness. For example, new concerning adopters with limited capacity frequentlystart with simple models as they are much feasible to the operationalisation, and conduct their practice as well as skillset over time. Companies would specifically benefit from the guidance on the effective methodologies of procedures for versatile purposes.

The relative carbon risk and absolute carbon risk is shown based on the dynamic common factor model. The graphical presentation of absolute versus relative carbon risk is measured in this research. The model is estimated by the Kalman filter. Systematic carbon risk demonstrates the common market risk measure based on market beta $\beta_{\text {mkt }}$ (general carbon risk exposure, such as market repricing risk). The following dynamic common factor model is used here:

$R_{i}(t)=R(t)^{T} \beta_{i}(t)+\epsilon_{i}(t)$

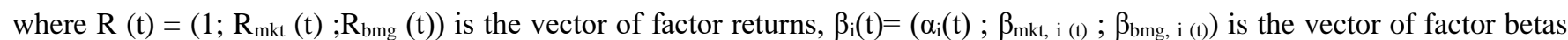
and $\epsilon_{\mathrm{i}}(\mathrm{t})$ is a white noise. The BMG factor could be stated as Fama-French risk concerning factor that is based on the scoring ranking system (BGS or brown green score).

The much frequently testimony of hindrance in constructing climate criteria scenarios is the lack of quality climate-related risk data that is appropriate for financial use. As scenario adopters seek access to verifiable, comparable, and decision-useful 
relevant data to feed their models, they are confronted with three distinct gaps. First, although plausible data on physical risks noticeably are accessible in the arena scientific field, they are particularly not tailored towards financial institutions as well as cannot be straightforwardly applied as the scenario inputs. Therefore, firms significantly find it complex to appropriately translate that the data into related financial insights. Second, established market-related data sources that were often deliberated for the policymakers rather than the investors. They depict an optimistic transition plan of climate change pathways that governments want to achieve, rather than the majority realistic path that economies will adopt. Finally, financial institutions seeking to do scenario analysis at the firm level must collect data from each of their portfolio companies. Furthermore, the number of organizations that provide climate-related disclosures is insufficient to provide support at the appropriate degree of granularity. Companies are currently being urged by lenders and investors to provide meaningful reports to stakeholders.

\section{RESULTS}

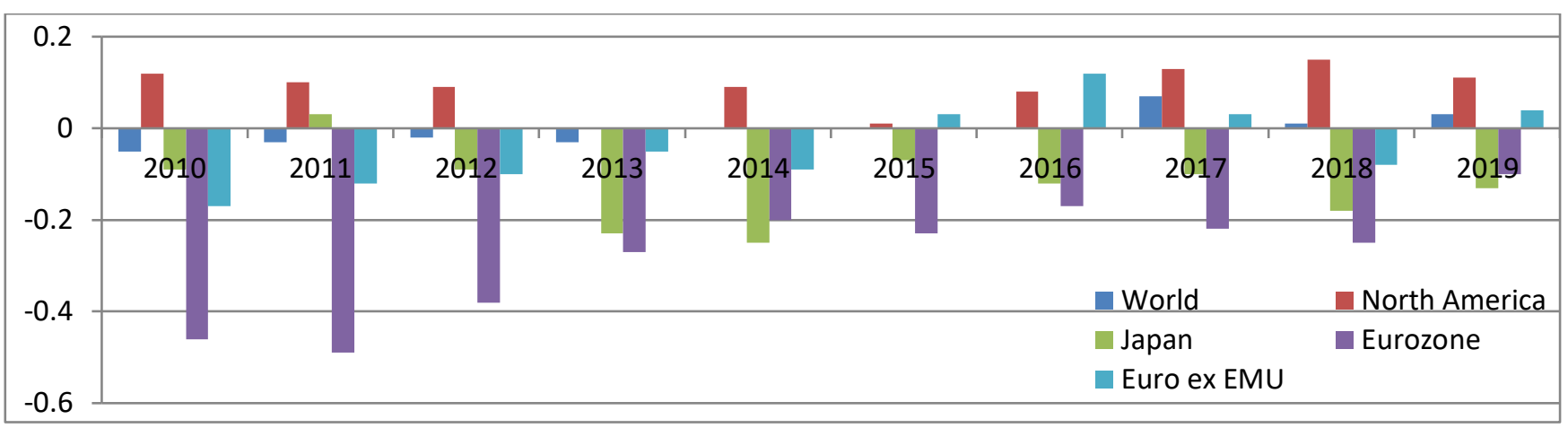

Figure 1: Region-wise dynamics of the average relative concerning carbon risk

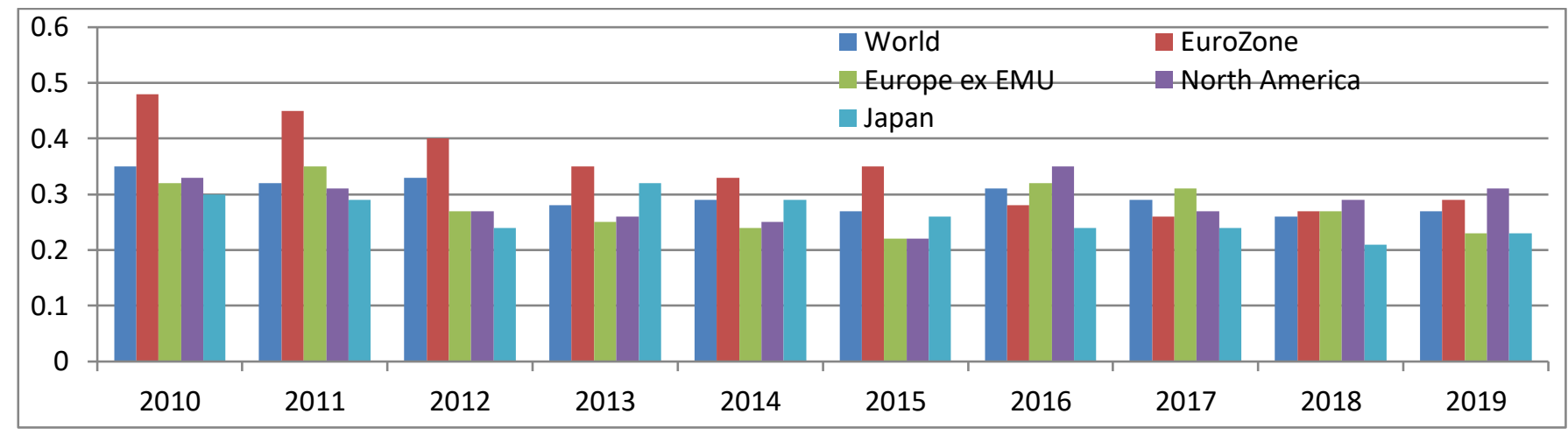

Figure 2: Region-wise dynamics of the average absolute concerning carbon risk

Based on the dynamic common factor model, absolute versus relative carbon risk is measured in this research. The model is estimated by the Kalman filter. According to the graphical presentation, the relative carbon risk in North America is in a higher trend. Then appears chronologically portraying low carbon risk concerning countries portfolio are Japan, Europe and Eurozone respectively. The average absolute carbon risk concerning countries according to descending series are as follows: Eurozone, Europe, North America, Japan. According to the global region perspective, the absolute carbon risk is higher than the relative carbon risk.

\section{DISCUSSION}

Climate concerning change has paved the world way to a riskier place. Heatwaves, hurricanes, droughts, and coastal region flooding not only endanger human lives and livelihoods but can also have serious long-term financial effects for a country. According to the IMF significant research (Pragyan et. al., 2020), it has resulted that the country's resilience or vulnerability to climate-related change can portray a direct upshot on its long term creditworthiness, its costs in regard to borrowing, ultimately, way to the likelihood this might default over its national sovereign debt. In their working paper, Delis et al. (2019) explored the climate policy risk and the price of bank loans. The economic long term consequences of climate-specific change have enormously been known throughout years, but distinguished research on showing how climate-specific change affects overall sovereign risk has rigorously been limited. These findings render evidence on the cross-sectional relationship between climate explicit change and sovereign specific credit ratings. The research constructs on similar rigorous analysis that, for the initial time, links the climate change volatility to sovereign consequences of default risk. Our research enormously has similarly resulted in a connection co-relation between climate-specific shocks and the sovereign explicit bond yields. 

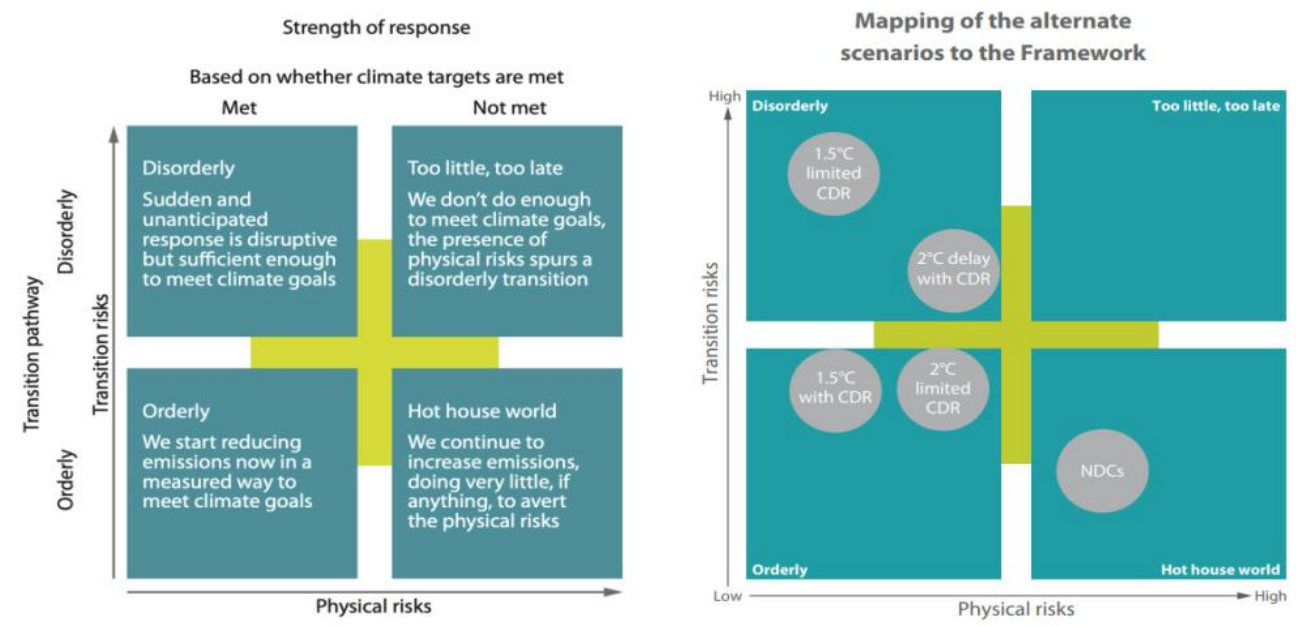

Figure 3: Integration of Physical and Transition Scenarios Based on NGFS Climate Scenarios Framework

One recurring remarkable theme amid overall these identical findings is that the financial risks co-created byclimate-specifics are felt much acutely by dint of developing economies, especially those which are not sufficiently prepared, including since the reason of the lack concerning policy space, to address the climate shocks. Based on climate-specific credit score, it might be stated so as to, the higher understanding regarding how climate-specific change eventually affects sovereign or national credit ratings that could provide important guidance on the sphere of how much the governments, as well as firms, can securely borrow and the amount of quantity it will expense them.

Being ambitious, long-term emissions reduction goals were significantly set in 2020 by major economies as well as some leading prestigious financial firms - 2021 is the timeline for the concrete plans that are yet to be found as reality. The major global or worldwide economic players inaugurated new rules concerning the game during 2020 - the hard target The big global or worldwide economic actors established new rules for the game in 2020, with a firm objective of net-zero carbon emissions by 2050. The European Union, Japan and the United Kingdom predictably declared their net-zero focused targets in the year 2020. The world's intense carbon emitter, China, declared that they in the long run would reach net-zero by the year 2060. With United States President-elect Joe Biden's intention in accordance to put the U.S. on an irrevocable path to the netzero by the year 2050, the dominant worldwide economies of nations are accounted for. Canada followed the suit in accordance with Bill C-12: The Carbon Accountability Act which is remarkably expected to pass in the year 2021, legislating the net-zero by tear 2050. This is in the line with vigorous expectations under the specific Paris Agreement, that was signed in 2015 by 197 nations, where parties remarkably agreed to restrict focusing the greenhouse gas discharges/emissions that cause the global warming towards levels that would create the limitation of temperature rise to 2 degree Celsius exceeding preindustrial levels.

TABLE 1

$\mathrm{CO}_{2}$ Emissions by Country

\begin{tabular}{lccc}
\multicolumn{1}{c}{ Rank Country } & CO2 emissions & Share total in GT & $\begin{array}{c}\text { CO2 emissions per capita } \\
\text { in }\end{array}$ \\
\hline China & $10: 06$ & $28 \%$ & $7: 2$ \\
\hline USA & $5: 41$ & $15 \%$ & $15: 5$ \\
\hline India & $2: 65$ & $7 \%$ & $1: 8$ \\
\hline Russia & $1: 71$ & $5 \%$ & $12: 0$ \\
\hline Japan & $1: 16$ & $3 \%$ & $8: 9$ \\
\hline Germany & $0: 75$ & $2 \%$ & $8: 8$ \\
\hline Iran & $0: 72$ & $2 \%$ & $8: 3$ \\
\hline South Korea & $0: 72$ & $2 \%$ & $12: 1$ \\
\hline Saudi Arabia & $0: 72$ & $2 \%$ & $17: 4$ \\
\hline Indonesia & $0: 72$ & $2 \%$ & $2: 2$ \\
\hline Canada & $0: 56$ & $2 \%$ & $15: 1$ \\
\hline Turkey & $0: 42$ & $1 \%$ & $4: 7$ \\
\hline UK & $0: 37$ & $1 \%$ & $5: 8$ \\
\hline France & $0: 33$ & $1 \%$ & $4: 6$ \\
\hline Italy & $0: 33$ & $1 \%$ & $5: 3$ \\
\hline
\end{tabular}

Source: World Bank Open Data, https://data.worldbank.org/topic/climate-change

Climate specific change volatility has no vital impact on the bond spreads as well as credit ratings with respect to advanced economies, but the enormous effect on the emerging markets as well as developing economies presumably is much higher due largely towards weaker capability towards adapt to and diminish the consequences in accordance to climate change. A boost of 10 points in percentage terms paves to climate change significant vulnerability is enormously associated with the increase 
of above 150 basis units of points in the long-standing government bond spreads in regard of emerging economy markets and the developing economies, while a vital improvement of the 10 percentage points concerning climate change, in terms of resilience, is enormously associated with the decrease of the 37.5 basis terms points with regard to bond spreads. On average, which is five times higher than the time when all countries in a regardless manner are counted. Giuzio et. al (2019) discussed the basic contingency moments as consequences of climate change and effects on financial stability in their paper.

Without sufficient action, climate-specific change is an unavoidable reality cross-wise the world. Rising the temperature level, changing the weather patterns, melting the glaciers, intensifying the storms and rising the sea levels unquestionably create vulnerabilities, specifically in the low-income countries. As countries helplessly seek a sustainable recovery path from the sequential effects of the outbreak of the COVID-19 pandemic, the benefits for climate resilience enormously are clear. Particularly, developing economies pertaining with limited financial capacity could get privilegedfrom alternative cross-wise instruments including the catastrophe insurance as well as debt-for-nature integrated swaps designed in accordance to mobilize the resources for the investments to achieve resilient infrastructure as well as environmental conservation-related in the time of reducing the credit relevant debt burden.

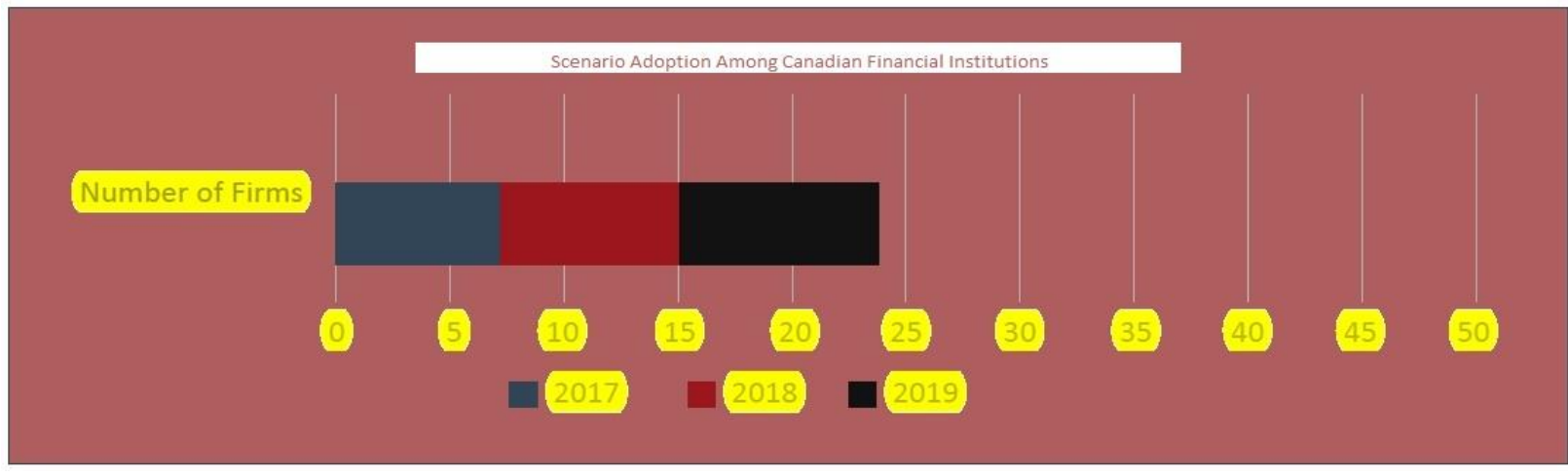

Figure 4: Climate-related Disclosure of Financial Sector in the Canadian Specific Financial Industry: Three-Year Based Progress Report

Meanwhile, pursuing the cost-effective climate climate-specific mitigation as well as the adaption of strategies; building infrastructural resilience towards climate risks, including by dint of resilient infrastructure; strengthening the financial resilience by fiscal buffers as well as insurance such, and to improve economic diversification towards reducing excessive reliance taking place in the arena of climate-sensitive specific sectors can simplify the strain related to climate change over public finances as well as reduce the overall cost of the borrowing that are associated along with lesser credit ratings.

\section{LIMITATIONS AND FUTURE RECOMMENDATIONS}

For the broader adoption of blended finance, a large numerical number of actors within the finance specific industry must playa significant role. Here are the six considerations which can be put into operation today:

1. It should be made the involvement of the chief investment officers, analysts and portfolio managers within the mainstream. Issues related to ESG, impact, climate as well as the SDGs enormously tend to become the domain in regard of sustainability resilience departments, but they classically do not allot money or possess the necessary finance efficacy to structure the blended finance-related deals. This requires significantly the inducement of 'mainstream' investment panels.

2. The option of encouraging these noteworthy mainstream investment populace should be undertaken to interact by means of those seeking towards structuring blended finance remedies: The associated people who decide in accordance to the capital allotment for the huge institutional investors generally are not known to and accessible to, development banks, governments, companies and individuals seeking towards financing their projects. An international community network of investment experts' agreeable to become engaged on the blended finance significantly is required.

3. It is supposed to be given the proper time towards analysing blended finance immense opportunities. The complexity as well as customisation involved within blended finance resources the time spent on deals that is often not proportionally large comparing to the size in regard of the investment. In many relevant cases, involvement underthe majority of investment people may not lead towards investment rather to sharing their efficacy, which is at a standstill helpful. But they significantly need to be acquainted with the matter that this is tolerated or still encouraged - as this unlikely is to be referred to in their specific job descriptions.

4. It should be aware of inherent biases as well as unhelpful labeling alternatives before proceeding. Because of the subliminal signals in investment literature - images of wind farms and impoverished people, as well as references to the 'impact' or the SDGs - combined with the platforms through which deals connect with investors, mainstream investment people may already have prejudices about the 'investability' before even reading the document. Projects must therefore be clear about the riskreward potential and the justification for the specific need for public and 'concessionary' finance upfront. 
5. People should be included, as well as knowledge in the 'market maker' sector. Because designing blended finance arrangements is similar to arranging sophisticated M\&A (mergers and acquisitions) deals, it is necessary to have experts who are familiar with the realm of development and the SDGs. This will encourage the gathering of the appropriate parties as well as the customization of the connected investment to meet their risk-return profiles. Investment bankers and M\&A lawyers, for example, may make a significant contribution here.

6. It is necessary to seek the participation of asset owners. This study shows that pension funds and insurance firms want to put a lot of money into their investments, but they also want to make sure that the investments they make fit the responsibilities on their balance sheets. They would be interested in investment possibilities that meet both of these criteria, but they must be assured that their associated capital will be allocated in accordance with their basic needs.

Financial institutions have reported a staggering number of specific benefits as a result of applying the climate scenarios: Implicit risk resilience has improved. Understanding the critical implications of climate risk has tremendously aided financial institutions as they strive to improve their risk mitigation methods and limit the potential losses linked with both physical and transitional concerns. Additionally, it aids businesses in preparing for upcoming regulatory demands, such as climate-related stress testing and scenario disclosures of increased stakeholder participation. Transparency in scenario creation and results demonstrates to investors and stakeholders how the company remarkably considers their overwhelming interests and considerable concerns about climate-specific risk. This can lead to improvements in the company's public perception and reputation.

Financial markets and institutions have discovered market possibilities under sustainable associated financial product promotional offerings, and new growth associated opportunities might be appraised by distinct regimes of transition paths. These include new lending and investing markets, financial product innovations, and enhanced advising speciality services to assist customers with their major sustainable engagement.

The development of a climate risk culture might be mainstreamed with experts from many functions working together to build climate scenarios, resulting in increased climate risk awareness and internal buy-in. This improves the organization's risk culture.

Meanwhile, financial markets and institutions have faced several notable obstacles when it comes to incorporating climate scenarios into decision-making. With climate risk being a relatively new practice, guidance is needed to help related institutions grasp the many elements of the relevant financial materiality of the climate risk, as well as the rush to be prepared.

\section{CONCLUSION}

Many countries, particularly the poorest and low-income regions, have seen a considerable increase in the risk of credit or debt distress as a result of the pandemic and the consequent collapse in economic activity. A number of notable measures, such as the G20 debt relief for the world's most visible impoverished countries, have been revealed in order to avoid situations where servicing existing debt would exacerbate and hamper those countries' notable response to the crisis.

As many countries' debt portfolios, as well as their long-term significant sustainability, have been thoroughly scrutinized - and debt premia have notably risen as a result - the need to assess the critical need to incur current debts, as well as to improve transparency within sovereign borrowing, has become apparent. Several recent debt scandals indicate that debts are frequently wrongfully incurred, or that the reason for which they are implemented is incorrect.

Dealing with debt ex-post and ensuring that countries can deal with distress situations are critical. This has been demonstrated in a variety of restructuring settings. It's also crucial to deal with debt ex-ante, which entails determining whether or not countries should take on financial commitments and under what conditions. Focusing on debt relief will only address problems as they arise, rather than attempting to address the source of the problem.

\section{REFERENCES}

Afreen, M. (2021). Transition Assessment of the Bangladeshi Financial Market Stress Regimes: A Markov Switching Modeling Approach. International Journal of Social Sciences and Economic Review, 3(1), 07-11. https://doi.org/10.36923/ijsser.v3i1.98

Afreen, M. (2020). Construction of an Industry Cycle Indicator for Profitability Prediction Analysis of Aggregate Firms in Bangladesh. International Journal of Social Sciences and Economic Review, 2(4), 09-18. https://doi.org/10.36923/ijsser.v2i4.76

Ahmad, I. (2021). Emotional Regulation as a Remedy for Teacher Burnout in Special Schools: Evaluating School Climate, Teacher's Work-Life Balance and Children Behaviour. Frontiers in Psychology, $12,2460$. https://doi.org/10.3389/fpsyg.2021.655850

Delis, M. D., De Grei, K., and Ongena, S, (2019). " Being Stranded with Fossil Fuel Reserves? Climate Policy Risk and the Pricing of Bank loans". Climate Policy Risk and the Pricing of Bank loans (September). EBRD Working Paper, (231). http://dx.doi.org/10.2139/ssrn.3125017

Giuzio, M., Krusec, D., Levels, A., Melo, A. S., Mikkonen, K., and Radulova, P, (2019). "Climate change and financial stability". Financial Stability Review, 1, May Issue. URL: https://www.ecb.europa.eu/pub/financialstability/fsr/special/html/ecb.fsrart201905_1 47cf778cc1.en.html 
Hong, H., Li, F. W. and Xu, J., (2019). Climate risks and market efficiency, Journal of Econometrics 208(1), $265-281$. https://doi.org/10.1016/j.jeconom.2018.09.015

Ilhan, E., Krueger, P., Sautner, Z. and Starks, L. T., (2019). Institutional Investors' Views and Preferences on Climate Risk Disclosure, SSRN Electronic Journal. https://dx.doi.org/10.2139/ssrn.3437178

Pragyan, D., Davide, F., Jonathan, D. O., Nour, F. (2020). The Economic Effects of COVID-19 Containment Measures. IMF Working Papers. Volume 2020, Issue 58(1-44). ISBN: 9781513550251/1018-5941

Kolbel, J. F., Leippold, M., Rillaerts, J. and Wang, Q., (2021). Ask bert: How regulatory disclosure of transition and physical climate risks affects the cds term structure, Technical report, University of Zurich. https://dx.doi.org/10.2139/ssrn.3616324

Krueger, P., Sautner, Z. and Starks, L. T., (2020). The importance of climate risks for institutional investors, The Review of Financial Studies 33(3), 1067-1111. URL: RePEc:oup:rfinst:v:33:y:2020:i:3:p:1067-1111.

Liu, Y., Ott, M., Goyal, N., Du, J., Joshi, M., Chen, D., Levy, O., Lewis, M., Zettlemoyer, L. and Stoyanov, V., (2019). Roberta: A robustly optimized bert pretraining approach, arXiv preprint arXiv:1907.11692. https://arxiv.org/abs/1907.11692

Luccioni, A. and Palacios, H., (2019). Using Natural Language Processing to Analyze Financial Climate Disclosures, Proceedings of the 36th International Conference on Machine Learning, Long Beach, California.

Marquis, C., To_el, M. W. and Zhou, Y, (2016). Scrutiny, norms, and selective disclosure: A global study of greenwashing, Organization Science 27(2), 483-504. https://doi.org/10.1287/orsc.2015.1039

McFarland, J. M., (2009). Warming up to climate change risk disclosure, Fordham Journal of Corporate \& Financial Law, 14(2), 281-323. https: /docview/89068214

Michaels, A. and Gr• uning, M. (2017). Relationship of corporate social responsibility disclosure on information asymmetry and the cost of capital, Journal of Management Control 28(3), 251-274. DOI: 10.1007/s00187-017-0251-z

NGFS, (2019a). A call for action. climate change as as source of financial risk, Network for Greening the Financial System Report. https://www.banque-france.fr/search-es?term=network+greening+financial+systemthe

NGFS, (2019b). Macroeconomic and Financial stability. implications of climate change, Network for Greening the Financial System Technical Supplement of the First Comprehensive Report. https://www.banque-france.fr/searches?term=network+greening+financial+systemthe

Nowiski, N, (2018). Rising above the storm: Climate risk disclosure and its current and future relevance to the energy sector, Energy Law Journal 39(1), 1-46. https://www.eba-net.org/felj/energy-law-journal-volume-39-no1-2018/

Sautner, Z., van Lent, L., Vilkov, G. and Zhang, R., (2020). Firm-level climate change exposure, Available at SSRN 3642508. https://dx.doi.org/10.2139/ssrn.3642508

TCFD, (2017). Final Report: Recommendations of the Task Force on Climate-related Financial Disclosures, TCFD Report 11(1), 27-32. https://www.fsb-tcfd.org

TCFD, (2020). Status Report of the Task Force on Climate-related Financial Disclosure. https://www.fsb-tcfd.org

Varini, F. S., Boyd-Graber, J., Ciaramita, M. and Leippold, M., (2020). ClimaText: A dataset for climate change topic detection, Tackling Climate Change with Machine Learning (Climate Change AI) Workshop at NeurIPS, December 2020 .

\section{Author's Biodata:}

Maria Afreen: Dr. Maria Afreen holds a Ph.D. degree in "Financial Economics" from University Malaysia Sarawak,Malaysia with a merit-based scholarship. She has expertise in data analysis in the areas of Volatility Forecasting \& Macro-economic Modeling, Credit Risk Management, Constructing Risk Indicator \& Filtering tools. She has a remarkable number of high impact factor indexed peer-reviewed journal publication records at the international level. 